\title{
Enhancing Acidic Dye Adsorption by Updated Version of UiO-66
}

\author{
Naser Al Amery ${ }^{1}$, Hussein Rasool Abid ${ }^{1,2, *}$, Shaobin Wang ${ }^{3}$ (D) and Shaomin $\operatorname{Liu}^{1}$ (i] \\ ${ }^{1}$ Chemical Engineering, WA School of Mines: Minerals, Energy and Chemical Engineering, Curtin University, Australia \\ ${ }^{2}$ Environmental Department, Applied Medical Science, University of Karbala, Iraq \\ ${ }^{3}$ School of Chemical Engineering, University of Adelaide, Australia
}

ABSTRACT: In this study, two improved versions of UiO-66 were successfully synthesised. Modified UiO-66 and UiO-66-Ce were characterised to confirm the integrity of the structure, the stability of functional groups on the surface and the thermal stability. Activated samples were used for removal harmful anionic dye (methyl orange) (MO) from wastewater. Batch adsorption process was relied to investigate the competition between those MOFs for removing MO from aqueous solution. Based on the results, at a higher initial concentration, the maximum MO uptake was achieved by UiO-66-Ce which was better than modified-UiO-66. They adsorbed 71.5 and $62.5 \mathrm{mg} \mathrm{g}^{-1}$ respectively. Langmuir and Freundlich isotherms were employed to simulate the experimental data. In addition, Pseudo first order and Pseudo second order equations were used to describe the dynamic behaviour of MO through the adsorption process. The high adsorption capacities on these adsorbents can make them promised adsorbents in industrial areas.

Key words: Methyl Orange, UiO-66, Langmuir and Freundlich isotherms, Kinetic adsorption model, Adsorption equilibrium model

\section{INTRODUCTION}

Nowadays, significant amount of wastewater with colour has been created by various industries including textile, leather, paper, printing, dye stuff, plastic and so on [1]. Based on the high impact of the quality of water by colour, the removal of dyestuff from polluted water is becoming very important issue [1]. Besides, the high visibility of dye even with a small amount is undesirable. Additionally, many dyes are toxic and even carcinogenic [1-3].

According to the stability to light and oxidation reactions, the degradability of synthetic dyes become one of the most challenges to the environmentalists [3]. It is reported that physical, chemical and biological methods have been applied for the remediation of dyes in aqueous solution $[1,3-4]$. One of the most feasible techniques among the proposed methods, is adsorption process due to its high efficiency, economic, and simplicity of design as well as operation [3-4].

Methyl orange (MO) is classified as a common acidic (anionic) dyes, which has been broadly used in many industries including textile, printing, paper, food and pharmaceutical industries, wood, silk, and research laboratories [2, 4]. The toxicity of $\mathrm{MO}$ has drawn the attention of researcher to the importance of the removal of this synthetic dye [2-4]. According to the above-mentioned explanation, MO was chosen to be examined in present study as a typical acidic dye. For the purpose of removal this kind of cationic dye, many solid materials were used as adsorbents to decolour the contaminated wastewater like activated carbon [5-6], graphene oxide [7], Layered double Hydroxide (LDH) [8] and zeolites [9] .
Metal-organic frameworks (MOFs) (hybrid materials) are class of extended structure crystalline solid porous materials which have been used widely in many applications [10]. The characteristics of MOFs including structural and functional tunability have led to explosive growth in their applications via extensive research during the last two decades [11]. Therefore, they have been used in several applications like gas and vapour storage, molecular separations, chemical catalysis, chemical sensing, ion exchange, drug delivery and hazardous materials [12-13]. They are good alternative adsorbents for removal of MO from aqueous solutions [14].

Because of lack of studies in MO removal using MOFs, the present study used the modified $\mathrm{UiO}-66$ and $\mathrm{UiO}-66-\mathrm{Ce}$ as structural sable porous materials to eliminate $\mathrm{MO}$ from wastewater. These samples were well characterised. Then, they are tested for adsorption of anionic dye (MO) at room temperature. The results proved high adsorption affinity of MO toward these adsorbents. The experimental data were fitted by kinetic and equilibrium adsorption models to investigate the type of the adsorption process and the energetic characteristics of the adsorbent's surface respectively. That can suggest an opportunity of using them as alternative sorbents instead of the conventional adsorbents for removal ionic dyes from wastewater.

$\begin{array}{ll}\text { Received } & \text { : December 25, 2019 } \\ \text { Revised } & \text { : January 27, 2020 } \\ \text { Accepted } & \text { : Febaruary 5, 2020 }\end{array}$




\section{MATERIALS AND METHODS}

\subsection{Synthesis and Activation}

All chemicals were supplied by Sigma Aldrich-Australia without further purifications. UiO-66-Ce was solvothermally synthesised under autogenous pressure. An exact amount of terephthalic acid (0.3771 g, $2.27 \mathrm{mmol}$; Sigma-Aldrich, 98\%) was mixed with $31.387 \mathrm{~mL}$ of DMF (Sigma-Aldrich, 99\%). Then the mixture was stirred for 10 min till a clear solution was formed. After that $\mathrm{ZrCl}_{4}(0.529$ g, $2.27 \mathrm{mmol}$; Sigma-Aldrich, 99\%) was added into the solution and stirred for $5 \mathrm{~min}$. Then $\mathrm{CeN}_{3} \mathrm{O}_{9} \cdot 6 \mathrm{H}_{2} \mathrm{O}(0.1971$ g, $0.000454 \mathrm{mmol}$; Sigma-Aldrich, $99 \%$ ) was added to the reactants and stirred for $15 \mathrm{~min}$. The mixture of reactants was loaded into a Teflon-lined autoclave, sealed and placed in a preheated oven at $393 \mathrm{~K}$ for $24 \mathrm{hr}$. White powder of $\mathrm{UiO}$ -66-Ce was collected by centrifugation and washed with a DMF at least three times. Then the product was dried and immersed in absolute methanol (100\%, Sigma Aldrich) for 5 d. eventually, it was filtered, dried and heated under vacuum at $473 \mathrm{~K}$ overnight prior to use for adsorption.

Modified UiO66 was synthesised solvothermally according to a reported procedure by a single-solvent method [15]. A solution of $32 \mathrm{~mL}$ of DMF was divided equally into two batches. In the first batch, $2.27 \mathrm{mmol}$ of terephthalic acid was added and mixed for $15 \mathrm{~min}$ and then $\mathrm{NH}_{4} \mathrm{OH}(0.4 \mathrm{~mL}, 2 \mathrm{M})$ was added dropwise to this mixture. In the second batch, $(0.53 \mathrm{~g}, 2.27 \mathrm{mmol})$ of $\mathrm{ZrCl}_{4}$ was mixed with the solvent for approximately $30 \mathrm{~min}$. After that, both batch solutions were mixed in a single pot for approximately $20 \mathrm{~min}$. Finally, the resulting solution was placed inside a 45 $\mathrm{mL}$ Parr PTFE-lined stainless-steel vessel (Parr Instrument Company, USA) and placed in an oven at $393 \mathrm{~K}$ for $24 \mathrm{hr}$. After cooling to room temperature, the centrifugation was used to separate white gel-like material, which was dried in an oven at $353 \mathrm{~K}$ for $24 \mathrm{hr}$. For activation of modified-UiO66 , a solvent exchange method by chloroform was used by mixing $0.1 \mathrm{~g}$ of a synthesised material in $50 \mathrm{~mL}$ of chloroform for $30 \mathrm{~min}$, and then keeping soaked for $5 \mathrm{~d}$. Then, the product was filtered by vacuum filtration and dried in the oven at $373 \mathrm{~K}$ for $2 \mathrm{hr}$. The final product was heated under vacuum at $473 \mathrm{~K}$ for $2 \mathrm{~d}$.

\subsection{Characterization}

Thermogravimetric analysis of the adsorbents were checked by a thermogravimetric analysis (TGA) instrument (TGA/DSC1 STARe system-METTLER TOLEDO). The samples were loaded into an alumina pan and heated to 1173 $\mathrm{K}$ at a rate of $5 \mathrm{~K} \mathrm{~min}^{-1}$. The air flow rate was maintained at $10 \mathrm{~mL} \mathrm{~min}^{-1}$.

FTIR spectra (Spectrum 100-FT-IR Spectrometer, Perkin-Elmer) were obtained to check the stability of the functional groups on the organic ligands. The spectrums were scanned from 650 to $4000 \mathrm{~cm}^{-1}$ with a resolution of 4 $\mathrm{cm}^{-1}$ by using an attenuated total reflectance (ATR) technique. X-ray powder diffraction patterns were obtained with an X-ray diffractometer (D8 Advance-Bruker aXS) using Cu $\mathrm{K} \alpha$ radiation $(\lambda=1.5406 \AA$ ) . Quantachrome instrument (Autosorb-1) was used to determine the $\mathrm{N}_{2}$ adsorption/ desorption isotherm, BET surface area, pore size and pore volume of activated samples. The samples were firstly evacuated at $473 \mathrm{~K}$ for $24 \mathrm{hr}$ prior to secondly use in the analysis at $77 \mathrm{~K}$. Elemental analysis was done by The NexION $^{\circledast}$ 300/350 - ICP-MS (PerkinElmer) and Optima 8300ICP-OES (PerkinElmer).

\subsection{Adsorption Process}

An aqueous stock solution of $\mathrm{MO}$ (1000 ppm) was prepared by dissolving $\mathrm{MO}\left(\mathrm{C}_{14} \mathrm{H}_{14} \mathrm{~N}_{3} \mathrm{NaO}_{3} \mathrm{~S}, \mathrm{MW}\right.$ : 327.34, Sigma-Aldrich) in deionized water. Aqueous solutions with different concentration of MO were prepared by successive dilution of the stock solution with water. Spectrophotometer (UV spectrophotometer-Jasco V-670) was used to determine the actual absorbance at the wavelength of 464 $\mathrm{nm}$ for each standard concentration. Then the calibration curve was obtained for the concentrations ranged from 5-100 ppm.

Prior to use in adsorption study, the adsorbents (modified UiO-66 and UiO-66-Ce) were dried overnight under vacuum at $373 \mathrm{~K}$. The several glass containers were cleaned, dried and filled up to $20 \mathrm{~mL}$ with $\mathrm{MO}$ of different concentrations ranged from 10 to $75 \mathrm{ppm}$. After that, the exact amount of an adsorbent $(20 \mathrm{mg})$ was mixed with $\mathrm{MO}$ in the containers by magnetic stirrer and maintained at a time from $5 \mathrm{~min}$ to $24 \mathrm{hr}$ at $298 \mathrm{~K}$. The samples for analysis were collected by syringe filter at different sampling interval. A supernatant was used in UV spectrometer for analysis.

The uptake of an adsorbent at any time and equilibrium time is expressed as shown in Equation (1) and (2), accordingly. However, removal efficiency of $\mathrm{MO}$ is calculated based on Equation (3) [16].

$$
\begin{aligned}
q_{t} & =\left(C_{0}-C_{t}\right) \frac{V}{m} \\
q_{e} & =\left(C_{0}-C_{e}\right) \frac{V}{m} \\
R \% & =\frac{\left(C_{0}-C_{t}\right)}{C_{0}} X 100
\end{aligned}
$$

Where:

$\mathrm{q}_{\mathrm{t}}$ : Amount of $\mathrm{MB}$ adsorbed in a specific weight of the adsorbent at any time $\mathrm{t}\left(\mathrm{mg} \cdot \mathrm{g}^{-1}\right)$,

$\mathrm{q}_{\mathrm{e}}$ : Amount of MB adsorbed in a specific weight of the adsorbent at equilibrium (mg. $\left.\mathrm{g}^{-1}\right)$,

$\mathrm{C}_{0}$ : Initial concentrations of $\mathrm{MB}$ solution at time zero $(\mathrm{mg}$ $\left.\mathrm{L}^{-1}\right)$,

$\mathrm{C}_{t}$ : Concentration of $\mathrm{MB}$ solution at time $\mathrm{t}\left(\mathrm{mg} \mathrm{L}^{-1}\right)$,

$\mathrm{C}_{e}$ : Concentration of $\mathrm{MB}$ solution at equilibrium $\left(\mathrm{mg} \mathrm{L}^{-1}\right)$,

$\mathrm{V}$ : volume of $\mathrm{MB}$ solution in the adsorption batch process (L),

$\mathrm{R} \%$ : Removal efficiency $\mathrm{MB}$,

$\mathrm{m}$ : The specific weight of the modified UiO-66 or UiO-66 -Ce in $(\mathrm{g})$ used in the adsorption batch process.

Experimental adsorption capacities were fitted by two kinetic models including pseudo-first order and pseudosecond models to determine the adsorption rate and identify the type of $\mathrm{MO}$ adsorption [17-20]. Moreover, the experimental data were also fitted by the Langmuir and Freundlich adsorption isotherm to describe the adsorption equilibrium isotherm of MO on the modified UiO-66 and UiO-66-Ce samples [17-19, 21]. 


\section{RESULTS AND DISCUSSION}

Activation process by chloroform exchange process was very active to remove all unwanted chemicals from the pores. Also, It mostly removed the whole content of the second metal which was expected to be weakly coordinated on the structure of UiO-66 due to their high incompatibility with $\mathrm{Zr}^{+4}$. Therefore, trace of $\mathrm{Ce}^{+2} 0.1 \%$ has been investigated by the elemental analysis.
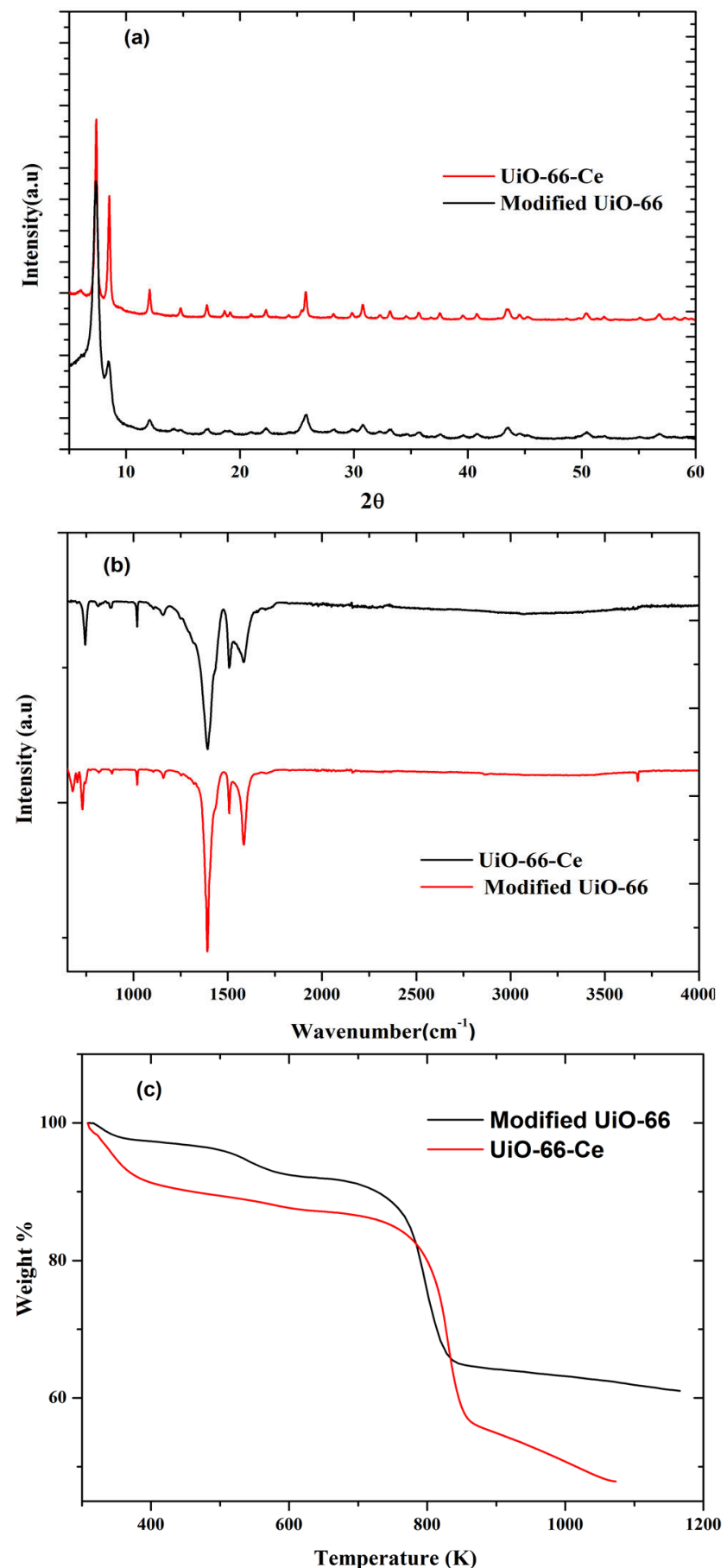

Fig. 1. (a) PXRD patterns, (b) FTIR Spectra and (c) TGA profiles for modified $\mathrm{UiO}-66$ and $\mathrm{UiO}-66-\mathrm{Ce}$.

Figure 1 (a) shows the PXRD pattern for UiO-66 samples, it was demonstrated that the structures were the same, similar to that in previous reported articles $[15,22]$. In addition, FTIR spectra of the samples in this study was shown in Figure1 (b), all functional groups which were seen on the surface of UiO-66 in previous studies [23] were observed and maintained on the surface of UiO-66-Ce and modified UiO-66. Formation of the crystalline UiO-66 was confirmed by presenting the peaks at the band of 1550-1630 $\mathrm{cm}^{-1}$ which referred to coordinated carboxylates with metal centers. On the other hand, the stretching variation band of $\mathrm{CO}$ bond in free carboxylic acid throughout the region of $1640-1670 \mathrm{~cm}^{-1}$ were mostly disappeared on all samples that can be a good indication for a good activation procedure used for the removing non-reacted carboxylic acid and free solvent from the pores. Furthermore, the thermal stability of those samples was investigated as demonstrated in Figure1 (c). All samples have the same thermal stability as that was mentioned in reported articles[15, 24]. They are stable up to about $750 \mathrm{~K}$.

Figure 2 shows the $\mathrm{N}_{2}$ adsorption/ desorption isotherms on the modified UiO-66 samples confirming their porosity. It seems these samples have pores in the long size range extending from micropore to macropore. Primary fillings in narrow micropores were achieved at low relative pressure up to 0.01 as shown in Figure 2. While the secondary fillings in wider micropore were filled on the long range of relative pressure up to 0.9 therefore this behaviour was represented by relatively horizontal line. However, hysteresis of desorption isotherm over adsorption isotherm referred to the presence of neck-bottle mesopores. In addition, rapid increasing of adsorption rate at higher pressure close to 0.999 can be a good evidence for presence of macropores.

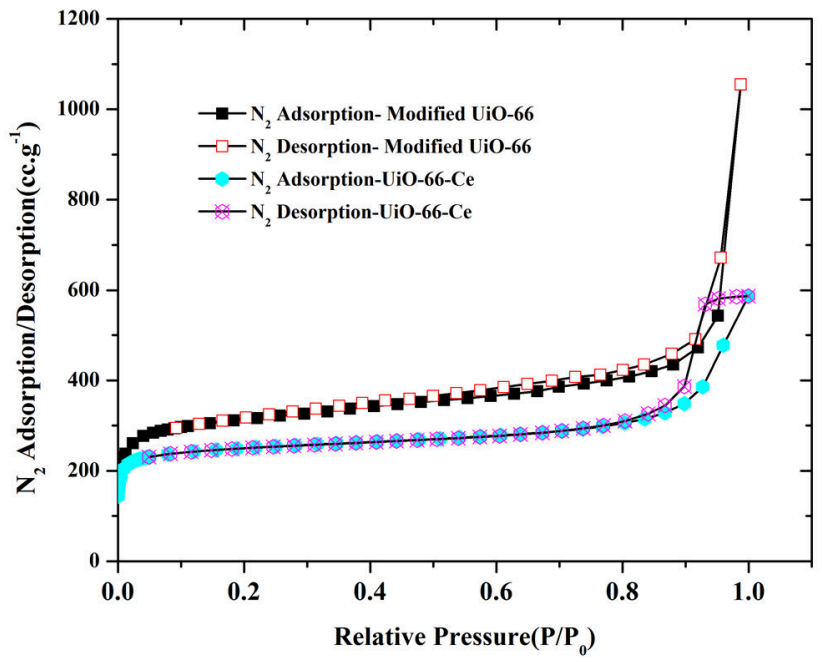

Fig. 2. $\mathrm{N}_{2}$ adsorption and pore size distribution of updated UiO-66 samples

Table 1 Textural properties of Zr-MOF samples

\begin{tabular}{ccccc}
\hline Material & $\begin{array}{c}\mathrm{BET} \\
\mathrm{m}^{2} \cdot \mathrm{g}^{-1}\end{array}$ & $\begin{array}{c}\text { External } \\
\text { surface } \\
\text { area } \\
\mathrm{m}^{2} \cdot \mathrm{g}^{-1}\end{array}$ & $\begin{array}{c}\text { Average } \\
\text { pore } \\
\text { volume } \\
\mathrm{cm}^{3} \cdot \mathrm{g}^{-1}\end{array}$ & $\begin{array}{c}\text { Average } \\
\text { pore } \\
\text { size } \\
(\mathrm{nm})\end{array}$ \\
\hline $\begin{array}{c}\text { Modified } \\
\text { UiO-66 }\end{array}$ & 1226 & 331 & 1.65 & 5.4 \\
$\begin{array}{c}\text { UiO-66- } \\
\mathrm{Ce}\end{array}$ & 911.85 & 224.45 & 0.91 & 4.00 \\
\hline
\end{tabular}


Table 1 displays the textural properties of the updated UiO-66 samples. Specific surface area (BET) was reduced in the structure of UiO-66-Ce, it was $911.85 \mathrm{~m}^{2} . \mathrm{g}^{-1}$. Whereas, the specific surface area of modified UiO-66 was approximately the same as that was published for UiO-66. It was $1226 \mathrm{~m}^{2} \cdot \mathrm{g}^{-1}$. The pore volume and pore size were enhanced in all the samples, the largest pore volume and pore size were exposed by modified UiO-66 of $1.65 \mathrm{cc} . \mathrm{g}^{1}$ and $5.4 \mathrm{~nm}$ correspondingly. While they were $0.91 \mathrm{cc} . \mathrm{g}^{-1}$ and $4.00 \mathrm{~nm}$ in UiO-66-Ce. Consequently, the external surface area was 331 and $224.45 \mathrm{~m}^{2} \cdot \mathrm{g}^{-1}$ on the modified $\mathrm{UiO}-66$ and UiO-66-Ce respectively.

\subsection{Kinetics Adsorption Models}

Kinetics adsorption studies is crucial part due to the giving a good indication about one of the criteria for efficiency of adsorbent which is the rate of adsorption as well as give clear picture about the mechanism of adsorption. The linear relationship of pseudo first order model can be expressed in eq. $4[25]$ :

$$
\ln \left(q_{e}-q_{t}\right)=\ln \left(q_{e}\right)-k_{1} t
$$

While The linear form of pseudo second order model is given in eq. 5 [19]:

$$
\frac{t}{q_{t}}=\frac{1}{k_{2} q_{e}^{2}}+\frac{1}{q_{e}} t
$$

Where:

$\mathrm{q}_{\mathrm{e}}$ : amount adsorbed at equilibrium (mg. $\left.\mathrm{g}^{-1}\right)$.

$\mathrm{q}_{\mathrm{t}}$ : amount adsorbed at time $\mathrm{t}\left(\mathrm{mg} \cdot \mathrm{g}^{-1}\right)$.

$\mathrm{t}$ : contact time ( $\mathrm{min})$.

$\mathrm{k}_{1}$ : First order kinetic constant $\left(\mathrm{min}^{-1}\right)$

$\mathrm{k}_{2}$ : Second order kinetic constant $\left(\mathrm{g} \cdot \mathrm{mg}^{-1} \mathrm{~min}^{-1}\right)$

$\ln \left(\mathrm{q}_{\mathrm{e}}-\mathrm{q}_{\mathrm{t}}\right)$ versus $\mathrm{t}$ plot can lead to a straight line from which the value of $k_{1}$ and $\mathrm{q}_{\mathrm{e}}$ can be found from the slope and intercept value, accordingly [26-28]. In the same way, $t / q_{t}$ versus $t$ can be plotted to give linear relationship, from which $\mathrm{q}_{\mathrm{e}}$ and $\mathrm{k}_{2}$ can be computed [29-31].

To compare the adsorption kinetics precisely, the experimental adsorbed amount changed with time are fitted with pseudo-first-order and pseudo-second-order kinetic models [17-19, 32-34] as shown in Figure 3 ( a, b, c, d). Tables 2 and 3 are tabulated the obtained parameter of the rate constant studies for various initial concentrations of MO by fitting the experimental data to the pseudo-firstorder and second-order equations. The results of the correlation coefficient $\left(\mathrm{R}^{2}\right)$ of the pseudo-first-order and pseudo-second-order adsorption models were revealed that $\mathrm{R}^{2}$ values of pseudo-second-order equation has higher values (greater than 0.99 ) compared to $\mathrm{R}^{2}$ values of pseudo-firstorder equation, and its calculated equilibrium adsorption capacity $\left(\mathrm{q}_{\mathrm{e}, \mathrm{cal}}\right)$ is consistent with experimental one $\left(\mathrm{q}_{\mathrm{e}}\right)$. Consequently, the pseudo-second-order adsorption mechanism is predominant for the adsorption of dye. Therefore, the overall rate of $\mathrm{MO}$ uptake on updated $\mathrm{UiO}-$ 66 samples seems to be controlled by the chemisorption processes [35] including valence forces through sharing or exchange of electrons $[20,36]$.
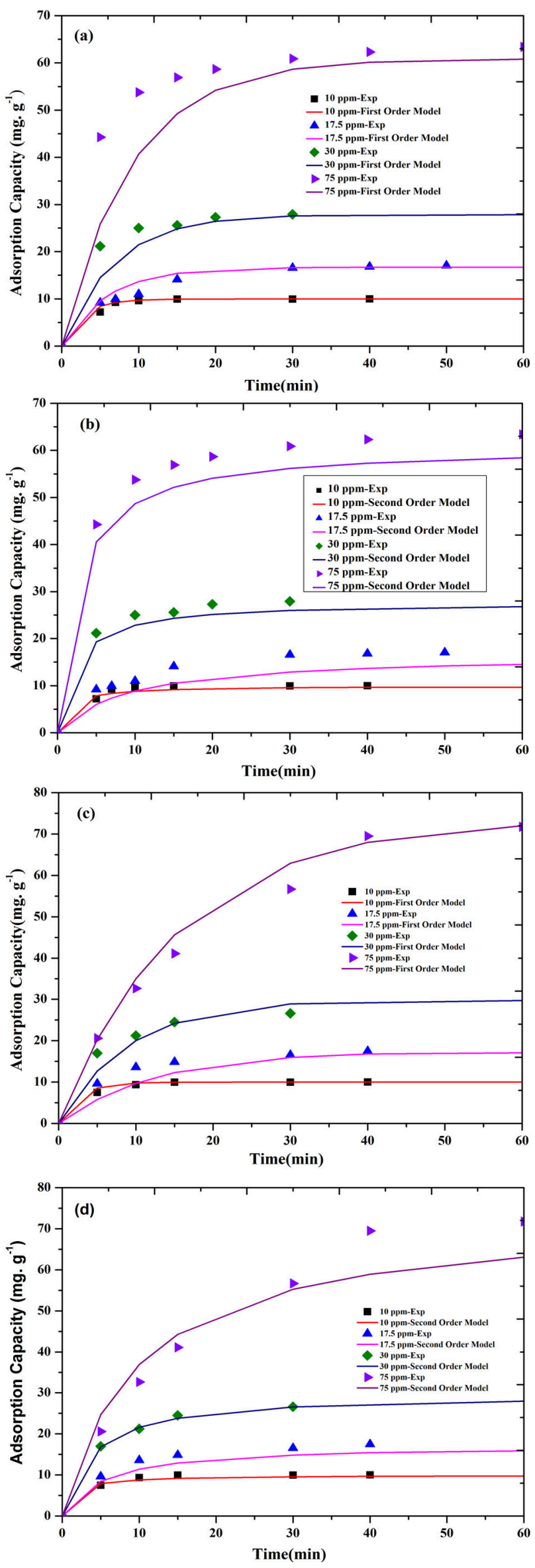

Fig. 3. Fitting of Experimental data by first order and second order kinetic models for adsorption of $\mathrm{MO}$ on modified UiO-66 (a, b), and UiO-66-Ce (c, d) 
Table 2 Pseudo-First-order kinetics constants $k_{1}\left(\mathrm{~min}^{-1}\right)$ and correlation coefficients $\left(\mathrm{R}^{2}\right)$ for adsorption of MO on updated UiO-66 samples

\begin{tabular}{ccccccccc}
\hline & \multicolumn{2}{c}{$10 \mathrm{ppm}$} & \multicolumn{2}{c}{$17.5 \mathrm{ppm}$} & \multicolumn{2}{c}{$30 \mathrm{ppm}$} & \multicolumn{2}{c}{$75 \mathrm{ppm}$} \\
\cline { 2 - 9 } Adsorbent & $\mathrm{k}_{1}$ & $\mathrm{R}^{2}$ & $\mathrm{k}_{1}$ & $\mathrm{R}^{2}$ & $\mathrm{k}_{1}$ & $\mathrm{R}^{2}$ & $\mathrm{k}_{1}$ & $\mathrm{R}^{2}$ \\
\hline Modified UiO-66 & 0.37 & 0.98 & 0.17 & 0.97 & 0.15 & 0.93 & 0.11 & 0.97 \\
UiO-66-Ce & 0.38 & 0.95 & 0.08 & 0.97 & 0.11 & 0.97 & 0.06 & 0.96 \\
\hline
\end{tabular}

Table 3 Pseudo-second-order kinetics constants $\mathrm{k}_{2}(\mathrm{~g} /(\mathrm{mg} \cdot \mathrm{min}))$ and correlation coefficients $\left(\mathrm{R}^{2}\right)$ for adsorption of MO on updated UiO-66 samples

\begin{tabular}{ccccccccc}
\hline \multirow{2}{*}{ Adsorbent } & \multicolumn{2}{c}{$10 \mathrm{ppm}$} & \multicolumn{2}{c}{$17.5 \mathrm{ppm}$} & \multicolumn{2}{c}{$30 \mathrm{ppm}$} & \multicolumn{2}{c}{$75 \mathrm{ppm}$} \\
\cline { 2 - 8 } & $\mathrm{k}_{2}$ & $\mathrm{R}^{2}$ & $\mathrm{k}_{2}$ & $\mathrm{R}^{2}$ & $\mathrm{k}_{2}$ & $\mathrm{R}^{2}$ & $\mathrm{k}_{2}$ & $\mathrm{R}^{2}$ \\
\hline Modified UiO-66 & 0.07 & 0.99 & 0.007 & 0.99 & 0.016 & 0.99 & 0.006 & 0.99 \\
UiO-66-Ce & 0.07 & 0.99 & 0.011 & 0.99 & 0.008 & 0.99 & 0.001 & 0.99 \\
\hline
\end{tabular}

That mechanism had been detected in the removal of $\mathrm{MB}$ and MO by adsorption onto an activated carbon [37]. It is also notable that in general the rate constant of the pseudo-second-order model $\left(\mathrm{k}_{2}\right)$ is decreases with increases of the initial MO concentration for the samples in this study. It appears from Table 3 that the rate constant $\left(k_{2}\right)$ increased on the adsorbents when initial concentration was set on 30 mg. $L^{-1}$ while it decreased at lower and higher concentration. That can be interpreted according to abundance of negative charges of MO which increases with increasing an initial concentration. Hence, the mobility of MO molecules may be affected by the initial concentration as it is first can be increased with increasing the concentration up to the overcharge limit then was decreased with raising the initial concentration further up.

Figure 3 (a,b, c, d) shows that most MO uptake occurred in the first $30 \mathrm{~min}$ of the contacting time indicating that in the beginning of the adsorption process, the diffusion rate of MO toward active sites on the adsorbents was increased and consequently the adsorption uptake of MOD was rapidly enhanced.

Furthermore, with increasing the contact time, the uploading of MO was slower due to lack availability of adsorptive sites as well as the likelihood of repulsive force between the molecules of MO themselves in the bulk solution. The adsorption mechanism of MO on the updated UiO-66 samples is controlled by the external surface area and pore size because MO has a large hydrophobic molecule [38]. Herein, all updated UiO-66 had larger average pore size which can be facile access for the molecules of MO. Consequently, the interaction between MO and the organic linkers is more likely to occur by $\pi-\pi$ stacking interactions. In addition, present of trace of $\mathrm{Ce}$ in the metal center of $\mathrm{Zr}$ enhanced its positive charge density as a result of that, the affinity of MO adsorption toward the metal center of the UiO-66-Ce sample was increased.

\subsection{Equilibrium adsorption models}

Equilibrium status of $\mathrm{MO}$ on the adsorbents at constant temperature is required because it is very important to determine the isotherm data and then to design the appropriate adsorption system. Many isotherm adsorption models were established to describe sorption equilibrium isotherms. The most important isotherm adsorption models that were widely employed to fit the equilibrium data were Langmuir [39] and Freundlich [40].

\subsubsection{Freundlich isotherm}

It is commonly used to describe a heterogeneous adsorption systems by using the following empirical formula;

$$
q_{e}=k_{F} C_{e}^{1 / n}
$$

Equation (6) is linearised and simplified in the following form of Equation (7);

$$
\ln \left(q_{e}\right)=\ln \left(k_{F}\right)+\frac{1}{n} \ln \left(C_{e}\right)
$$

Where:

$\mathrm{q}_{\mathrm{e}}$ : amount of dye sorbed at equilibrium per unit mass of sorbent $\left(\mathrm{mg} . \mathrm{g}^{-1}\right)$.

$\mathrm{C}_{\mathrm{e}}$ : the equilibrium concentration of dye in solution $\left(\mathrm{mg} \cdot \mathrm{L}^{-1}\right)$

$\mathrm{k}_{\mathrm{F}}$ : Freundlich equilibrium constants $\left(\mathrm{mg} . \mathrm{g}^{-1} \cdot\left(\mathrm{L} \cdot \mathrm{mg}^{-1}\right)^{1 / \mathrm{n}}\right)$ is an indicator of the adsorption capacity.

$1 / n$ : an empirical parameter refers to the adsorption intensity while $\mathrm{n}$ measures the deviation from linearity of the adsorption. The favourability of the adsorption systems may be tested by determining the reciprocal of the magnitude of the exponent $n$ value. When the value of $\mathrm{n}$ ranged from 1 to 10 , it can be concluded that the normal adsorption process is favourable. This behaviour is most common physical adsorption because of a decrease in adsorbate- adsorbent interactions with increasing the surface density [41].

From the straight-line plot of $\ln \left(q_{e}\right)$ vs $\ln \left(C_{e}\right)$, the values of $n$ and $k_{F}$ can be simply found from the slop and intercept, accordingly. The values of these parameters were significantly affected by the type of adsorbate and adsorbent. Therefore, they are obviously changed with using modified UiO-66, and UiO-66-Ce, as displayed in Table 4. 


\subsubsection{Langmuir isotherm}

Langmuir model [41] is built on many assumptions; the adsorbent has a uniform surface and its adsorptive sites are equivalent; and the molecules of adsorbates do not interact with themselves therefore a monolayer is made. [42]. Based on this theory, Langmuir empirically derived an equation which correlates between the numbers of active adsorption sites on the surface of adsorbent and the concentration of adsorbate. This correlation is called Langmuir Equation which is expressed as follow:

$$
q_{e}=\frac{q_{m} k_{L} C_{e}}{\left(1+k_{L} C_{e}\right)}
$$

Whereas the linear form of Langmuir model may be written as below:

$$
\frac{C_{e}}{q_{e}}=\frac{1}{q_{m}} C_{e}+\frac{1}{k_{L} q_{m}}
$$

Where:

qm : Langmuir maximum loading capacity $\left(\mathrm{mg}^{\mathrm{g}} \mathrm{g}^{-1}\right)$,

$\mathrm{k}_{\mathrm{L}} \quad$ : Langmuir constant related to the energy of adsorption and affinity of binding sites ( $\left.\mathrm{L} . \mathrm{mg}^{-1}\right)$,

$\mathrm{C}_{e}$ : the equilibrium concentration of dye in solution (mg. $\left.\mathrm{L}^{-1}\right)$

qe : amount of dye sorbed at equilibrium per unit mass of sorbent $\left(\mathrm{mg}\right.$. $\left.\mathrm{g}^{-1}\right)$. For obtaining the $\mathrm{q}_{\mathrm{m}}$ and $\mathrm{k}_{\mathrm{L}}$ from the experimental data, $\mathrm{C}_{e} / \mathrm{q}_{\mathrm{e}}$ can be plotted against $\mathrm{C}_{\mathrm{e}}$ yielding linear relationship with slop $\left(1 / q_{m}\right)$ and intercept $\left(1 / \mathrm{k}_{\mathrm{L}} \mathrm{q}_{\mathrm{m}}\right)$. The values of these parameters as well as the parameters of the Freundlich model were found for modified UiO-66 and UiO-66-Ce and listed in Table 4.

According to the Langmuir model Table 4 demonstrates that, the maximum sorption capacity of MO (qm) on the modified UiO-66 and UiO-66-Ce was 67.56 and $208 \mathrm{mg}$. $\mathrm{g}^{-1}$ respectively. The maximum adsorption capacity was a hugely deviated away from the experimental data in UiO-66-Ce while that was in a good agreement in the modified UiO-66, In addition, $\mathrm{K}_{\mathrm{L}}$ values in modified UiO-66 was much higher than that in $\mathrm{UiO}-66-\mathrm{Ce}$, it was 1.56 and 0.256 respectively. That indicates to strong interaction is likely to happen between $\mathrm{MO}$ and the active site on the surface of modified UiO-66 whereas this interaction is likely to be very weak in UiO-66-Ce. Furthermore, according to the Freundlich model, Table 4 displays that $\mathrm{K}_{\mathrm{F}}$ and $\mathrm{n}$ were 40.8 and 1.18; and 31.13 and 3.75 in UiO-66-Ce and modified UiO-66 respectively. That indicates that the adsorption rate of MO toward the surface of UiO-66-Ce was higher than that toward modified UiO-66. Also, UiO-66-Ce has a lower deviation from the linearity.

In Figure 4 displays that, adsorption of $\mathrm{MO}$ on $\mathrm{UiO}$ 66-Ce and modified UiO-66 was well fitted by Langmuir model. Our results are distinguished among other results from different researches as listed in Table 5 showing a good performance of updated $\mathrm{UiO}-66$ samples. Figure 5 demonstrates that the removal efficiencies of $\mathrm{MO}$ on the modified UiO-66 and UiO-66-Ce was the highest (99\%) at the lowest initial concentration used then it is slightly decreased on UiO-66-Ce with increasing the initial concentration. However, the removal efficiency was sharply dropped on modified UiO-66.

The expression of essential characteristics of the Langmuir isotherm is very important indication for the favourability of adsorption process which may be written based on a dimensionless constant separation factor $\left(\mathrm{R}_{\mathrm{L}}\right)$ as follow:

$$
R_{L}=\frac{1}{\left(1+k_{L} C_{0}\right)}
$$

Where:

$\mathrm{C}_{0}$ : the initial concentration of adsorbate $\left(\mathrm{mg} . \mathrm{L}^{-1}\right)$, $\mathrm{k}_{\mathrm{L}}:\left(\mathrm{L} \cdot \mathrm{mg}^{-1}\right)$ is Langmuir constant.

Type of the isotherm can be predicted from the $R_{\mathrm{L}}$ value indicating the favourability of the process of adsorption. It may be equal to zero, one, greater than one, or greater than zero and less than one proofing that the adsorption process is either irreversible, linear, unfavourable, or favourable, respectively. Figure 6 shows that all values of $R_{\mathrm{L}}$ are between $0<R_{\mathrm{L}}<1$ confirming that the normal adsorption of $\mathrm{MO}$ on UiO-66 samples are favourable. $\mathrm{RL}$ approached to zero at high concentration indicated that a further increasing in initial concentrations might lead to irreversible adsorption due to enhancing the attraction force with increasing the initial concentrations [22].
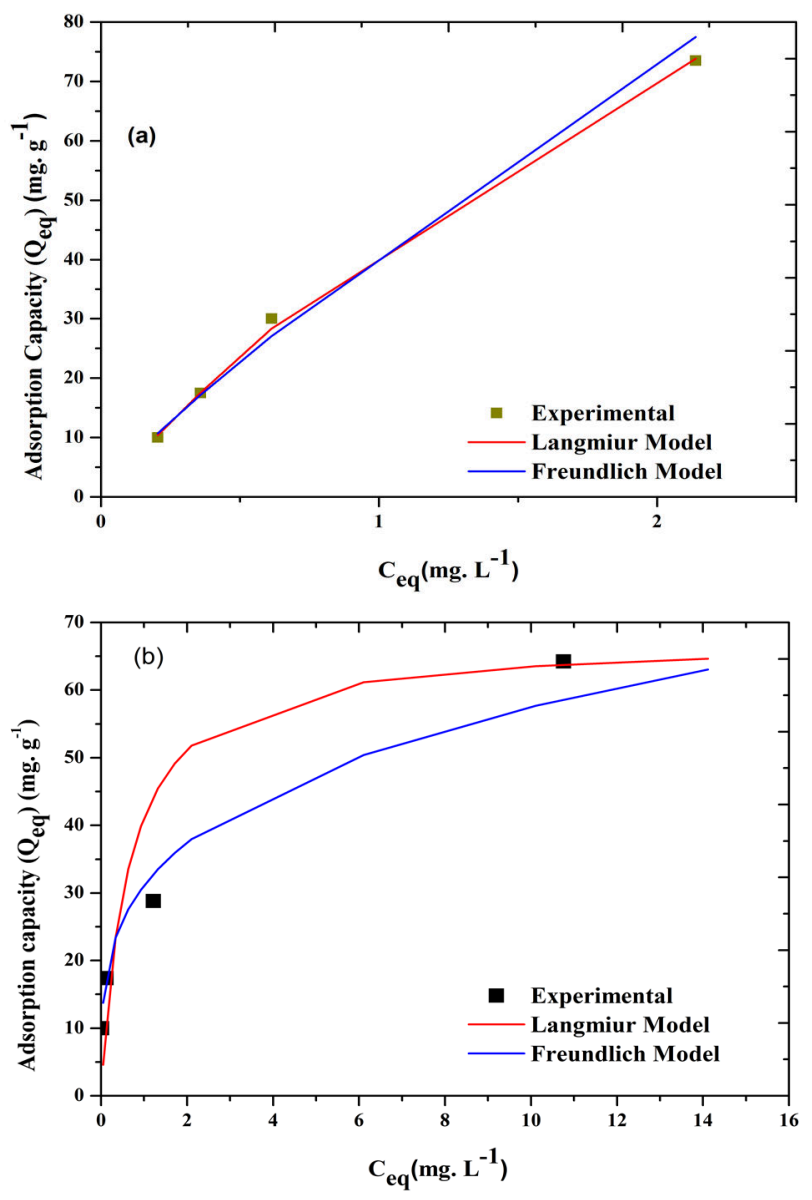

Fig. 4. Experimental data of MO adsorption isotherms and the non-linear fitting of Langmuir and Freundlich models on (a) UiO-66-Ce and (b) Modified UiO-66 


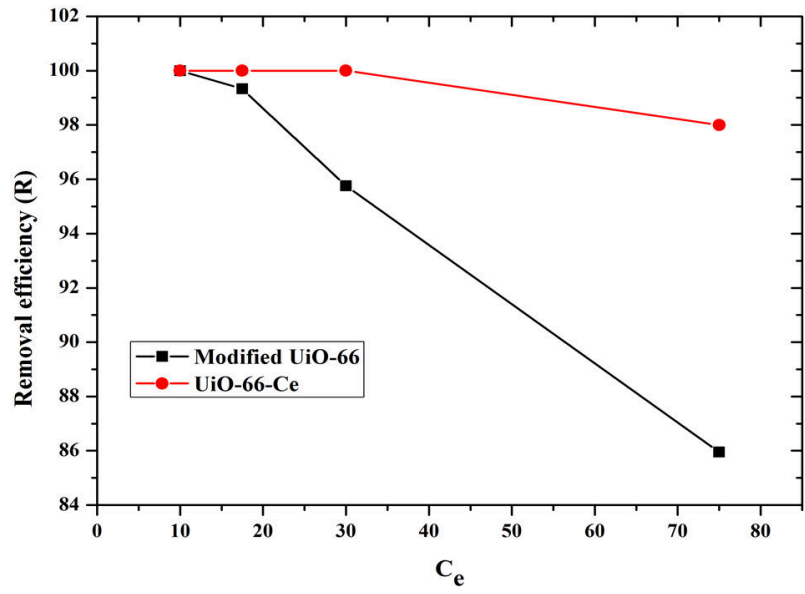

Fig. 5. Removal efficiency of $\mathrm{MO}$ on updated $\mathrm{UiO}-66$ samples

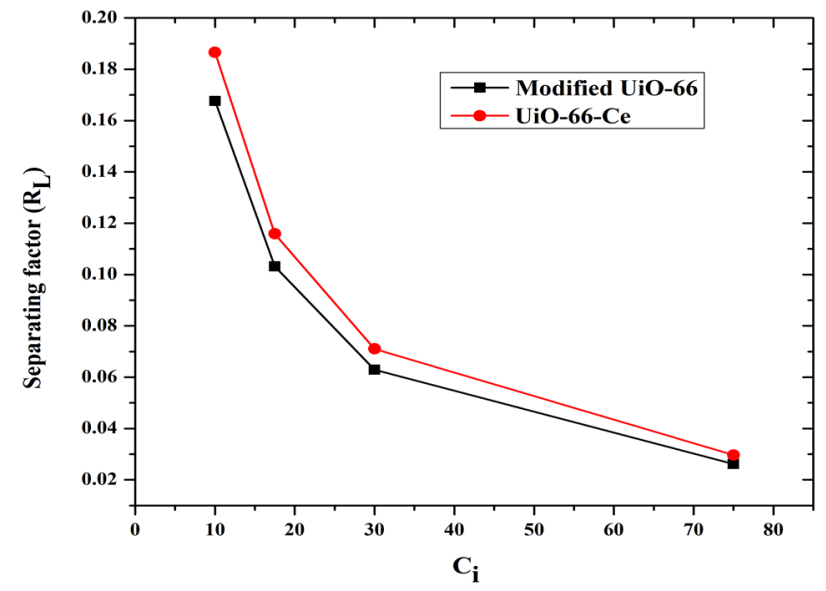

Fig. 6. Separation factor based on Langmuir isotherm in updated UiO-66 samples

Table 4 Calculated equilibrium constants $\left(\mathrm{k}_{\mathrm{L}}, \mathrm{k}_{\mathrm{F}}, \mathrm{q}_{\mathrm{m}}, \mathrm{n}\right.$, and correlation coefficients $\left.\left(\mathrm{R}^{2}\right)\right)$ adsorption of MO on Modified $\mathrm{UiO}-66$ and $\mathrm{UiO}-66-\mathrm{Ce}$ for $\mathrm{Ci}=10,17.5,30$, and $75 \mathrm{ppm}$.

\begin{tabular}{|c|c|c|c|}
\hline Adsorbent & $\begin{array}{l}\text { Adsorption isotherm } \\
\text { model }\end{array}$ & Parameters & $\mathrm{R}^{2}$ \\
\hline \multirow{2}{*}{$\mathrm{UiO}-66-\mathrm{Ce}$} & Langmuir & $\begin{array}{c}\mathrm{q}_{\mathrm{m}}=208 \mathrm{mg} \cdot \mathrm{g}^{-1} \\
\mathrm{~K}_{\mathrm{L}=} 0.256 \mathrm{~L} \cdot \mathrm{mg}^{-1}\end{array}$ & 0.964 \\
\hline & Freundlich & $\begin{array}{c}\mathrm{K}_{\mathrm{F}}=40.8\left(\mathrm{mg} \cdot \mathrm{g}^{-1}\right)(\mathrm{L} \cdot \mathrm{mg})^{0.313} \\
\mathrm{n}=1.18 \mathrm{~g} \cdot \mathrm{L}^{-1}\end{array}$ & 0.991 \\
\hline \multirow{2}{*}{ Modified UiO-66 } & Langmuir & $\begin{array}{l}\mathrm{q}_{\mathrm{m}}=67.56 \mathrm{mg} \cdot \mathrm{g}^{-1} \\
\mathrm{~K}_{\mathrm{L}}=1.56 \mathrm{~L} \cdot \mathrm{mg}^{-1}\end{array}$ & 0.983 \\
\hline & Freundlich & $\begin{array}{c}\mathrm{K}_{\mathrm{F}}=31.13\left(\mathrm{mg} \cdot \mathrm{g}^{-1}\right)\left(\mathrm{L} \cdot \mathrm{mg}^{-1}\right)^{0.458} \\
\mathrm{n}=3.75\left(\mathrm{~g} \cdot \mathrm{L}^{-1}\right)\end{array}$ & 0.985 \\
\hline
\end{tabular}

Table 5 The MO adsorption capacity onto different sorbents in comparison with the updated UiO-66 samples

\begin{tabular}{|c|c|c|}
\hline Adsorbent & $\mathrm{q}_{\mathrm{m}}\left(\mathrm{mg} \cdot \mathrm{g}^{-1}\right)$ & Reference \\
\hline Modified UiO-66 & 62.5 & This study \\
\hline $\mathrm{UiO}-66-\mathrm{Ce}$ & 71.5 & This study \\
\hline Hypercrosslinked polymeric adsorbent & 70.9 & {$[43]$} \\
\hline Metal Organic Framework (MIL-53) & 57.9 & {$[14]$} \\
\hline Multiwalled carbon nanotubes & 52.86 & {$[37]$} \\
\hline Chitosan & 34.83 & {$[44]$} \\
\hline modified montmorillonite & 24.00 & {$[45]$} \\
\hline Banana peel & 21 & {$[46]$} \\
\hline Orange peel & 20.5 & {$[46]$} \\
\hline Modified ultrafine coal powder & 18.52 & {$[47]$} \\
\hline graphene oxide & 16.83 & {$[7]$} \\
\hline Chitosan/kaolin $/ \gamma-\mathrm{Fe}_{2} \mathrm{O}_{3}$ & 14.2 & {$[48]$} \\
\hline Bottom ash & 13.35 & {$[2]$} \\
\hline De-oiled soya & 13.46 & {$[2]$} \\
\hline Activated carbon & 11.2 & {$[14]$} \\
\hline Activated alumina & 9.8 & {$[49]$} \\
\hline Diaminoethanesporopollenin biopolymer & 4.7 & {$[50]$} \\
\hline Bottom ash & 3.62 & {$[2]$} \\
\hline
\end{tabular}




\section{CONCLUSIONS}

Three adsorbents (UiO-66-Ce and modified UiO-66) were used for removal acidic dye (Methyl orange (MO)). They were synthesised in single pot solvothermal methods. The textural properties were improved and enhanced. The batch adsorption experiment was achieved at constant temperature to remove $\mathrm{MO}$ from the wastewater using the activated updated UiO-66 samples. The experimental data were fitted for kinetic adsorption and adsorption equilibrium isotherms. In regards to the kinetic adsorption, it was confirmed that the pseudo-second-order kinetics was dominated, indicating that the MO uptake on modified $\mathrm{UiO}$ -66 samples is controlled by the chemisorption processes. However, the adsorption isotherm of MO on all updated UiO-66 samples was in accordance with the Langmuir isotherm model verifying the adsorption of $\mathrm{MO}$ on adsorbents is monolayer adsorption and the adsorbent $\mathrm{s}$ are structurally homogeneous. Moreover, modified UiO-66 was the best adsorbent for MO removal at highest maximum adsorption capacity of $68.49 \mathrm{mg}$. $\mathrm{g}^{-1}$. These updated UiO-66 samples can be selected as candidates for industrial application for removal other contaminants from wastewater.

\section{AUTHOR INFORMATION}

\section{Corresponding Author}

*Email: Hussein.Abid@curtin.edu.au

\section{ORCID}

Shaobin Wang : 0000-0002-1751-9162

Shaomin Liu : :0000-0001-5019-5182

\section{REFERENCES}

[1] Crini, G., Non-conventional low-cost adsorbents for dye removal: A review. Bioresource Technology, 2006. 97(9): p. 1061-1085.

[2] Mittal, A., et al., Studies on the adsorption kinetics and isotherms for the removal and recovery of Methyl Orange from wastewaters using waste materials. Journal of Hazardous Materials, 2007. 148(1): p. 229-240.

[3] Chen, S., et al., Equilibrium and kinetic studies of methyl orange and methyl violet adsorption on activated carbon derived from Phragmites australis. Desalination, 2010.252(1): p. 149-156.

[4] Rafatullah, M., et al., Adsorption of methylene blue on low-cost adsorbents: A review. Journal of Hazardous Materials, 2010. 177(1): p. 70-80.

[5] Malarvizhi, R. and Y.-S. Ho, The influence of $\mathrm{pH}$ and the structure of the dye molecules on adsorption isotherm modeling using activated carbon. Desalination, 2010. 264(1-2): p. 97-101.

[6] Lorenc-Grabowska, E. and G. Gryglewicz, Adsorption characteristics of Congo Red on coal-based mesoporous activated carbon. Dyes and pigments, 2007. 74(1): p. 34-40.

[7] Robati, D., et al., Removal of hazardous dyes-BR 12 and methyl orange using graphene oxide as an adsorbent from aqueous phase. Chemical Engineering Journal, 2016. 284: p. 687-697.

[8] Zaghouane-Boudiaf, H., M. Boutahala, and L. Arab, Removal of methyl orange from aqueous solution by uncalcined and calcined MgNiAl layered double hydroxides (LDHs). Chemical Engineering Journal, 2012. 187: p. 142-149.

[9] Huang, M., et al., Photocatalytic discolorization of methyl orange solution by $\mathrm{Pt}$ modified $\mathrm{TiO} 2$ loaded on natural zeolite. Dyes and Pigments, 2008. 77(2): p. 327-334.

[10] Horcajada, P., et al., Flexible porous metal-organic frameworks for a controlled drug delivery. Journal of the American Chemical Society, 2008. 130(21): p. 6774-6780.

[11] Kitagawa, S., Metal-organic frameworks (MOFs). Chemical Society Reviews, 2014. 43(16): p. 5415-5418.

[12] Horcajada, P., et al., Metal-organic frameworks as efficient materials for drug delivery. Angewandte chemie, 2006. 118(36): p. 6120-6124.

[13] Farha, O.K. and J.T. Hupp, Rational Design, Synthesis, Purification, and Activation of Metal-Organic Framework Materials. Accounts of Chemical Research, 2010. 43(8): p. 1166-1175.

[14] Haque, E., et al., Adsorptive removal of methyl orange from aqueous solution with metal-organic frameworks, porous chromium-benzenedicarboxylates. Journal of Hazardous Materials, 2010. 181(1): p. 535-542.

[15] Abid, H.R., H.M. Ang, and S. Wang, Effects of ammonium hydroxide on the structure and gas adsorption of nanosized Zr-MOFs (UiO-66). Nanoscale, 2012.4(10): p. 3089-3094.

[16] Mouni, L., et al., Removal of Methylene Blue from aqueous solutions by adsorption on Kaolin: Kinetic and equilibrium studies. Applied Clay Science, 2018. 153: p. 38-45.

[17] Hameed, B. and A. Rahman, Removal of phenol from aqueous solutions by adsorption onto activated carbon prepared from biomass material. Journal of Hazardous Materials, 2008. 160(2): p. 576-581.

[18] Ho, Y.-S. and G. McKay, Pseudo-second order model for sorption processes. Process biochemistry, 1999. 34 (5): p. 451-465.

[19] Wang, S., H. Li, and L. Xu, Application of zeolite MCM-22 for basic dye removal from wastewater. Journal of colloid and interface science, 2006. 295(1): p. 71-78.

[20] Pathania, D., S. Sharma, and P. Singh, Removal of methylene blue by adsorption onto activated carbon developed from Ficus carica bast. Arabian Journal of Chemistry, 2017. 10: p. S1445-S1451.

[21] Lin, S.-H. and R.-S. Juang, Adsorption of phenol and its derivatives from water using synthetic resins and low-cost natural adsorbents: a review. Journal of environmental management, 2009. 90(3): 1336-1349.

[22] Zaboon, S., et al., Removal of monoethylene glycol from wastewater by using Zr-metal organic frameworks. Journal of Colloid and Interface Science, 
2018. 523: p. 75-85.

[23] Abid, H.R., et al., Nanosize Zr-metal organic framework (UiO-66) for hydrogen and carbon dioxide storage. Chemical Engineering Journal, 2012. 187: p. 415-420.

[24] Abid, H.R., et al., Adsorption of $\mathrm{CH} 4$ and $\mathrm{CO} 2$ on $\mathrm{Zr}$-metal organic frameworks. Journal of colloid and interface science, 2012.366(1): p. 120-124.

[25] Lagergren, S., About the theory of so-called adsorption of soluble substances. Sven. Vetenskapsakad. Handingarl, 1898. 24: p. 1-39.

[26] Wu, Z., et al., Adsorptive removal of methylene blue by rhamnolipid-functionalized graphene oxide from wastewater. Water Research, 2014. 67: p. 330-344.

[27] Gupta, N., A.K. Kushwaha, and M.C. Chattopadhyaya, Application of potato (Solanum tuberosum) plant wastes for the removal of methylene blue and malachite green dye from aqueous solution. Arabian Journal of Chemistry, 2016. 9: p. S707-S716.

[28] Chen, L., et al., High performance agar/graphene oxide composite aerogel for methylene blue removal. Carbohydrate Polymers, 2017. 155: p. 345-353.

[29] Fan, S., et al., Removal of methylene blue from aqueous solution by sewage sludge-derived biochar: Adsorption kinetics, equilibrium, thermodynamics and mechanism. Journal of Environmental Chemical Engineering, 2017.5(1): p. 601-611.

[30] Kumar, A. and H.M. Jena, Removal of methylene blue and phenol onto prepared activated carbon from Fox nutshell by chemical activation in batch and fixed-bed column. Journal of Cleaner Production, 2016. 137: p. 1246-1259.

[31] Albadarin, A.B., et al., Activated lignin-chitosan extruded blends for efficient adsorption of methylene blue. Chemical Engineering Journal, 2017. 307: p. 264 $-272$.

[32] Asfaram, A., et al., Rapid removal of Auramine-O and Methylene blue by $\mathrm{ZnS}: \mathrm{Cu}$ nanoparticles loaded on activated carbon: A response surface methodology approach. Journal of the Taiwan Institute of Chemical Engineers, 2015. 53: p. 80-91.

[33] Roosta, M., et al., Optimization of the ultrasonic assisted removal of methylene blue by gold nanoparticles loaded on activated carbon using experimental design methodology. Ultrasonics Sonochemistry, 2014. 21(1): p. 242-252.

[34] Auta, M. and B.H. Hameed, Chitosan-clay composite as highly effective and low-cost adsorbent for batch and fixed-bed adsorption of methylene blue. Chemical Engineering Journal, 2014. 237: p. 352-361.

[35] Ho, Y. and G. McKay, The sorption of lead (II) ions on peat. Water research, 1999.33(2): p. 578-584.

[36] Bhattacharyya, K.G. and A. Sharma, Kinetics and thermodynamics of methylene blue adsorption on neem (Azadirachta indica) leaf powder. Dyes and pigments, 2005. 65(1): p. 51-59.

[37] Mahmoudi, K., et al., Kinetics and equilibrium studies on removal of methylene blue and methyl orange by adsorption onto activated carbon prepared from date
pits-A comparative study. Korean Journal of Chemical Engineering, 2015.32(2): p. 274-283.

[38] Wu, Q.-y., et al., Hierarchically porous carbon membranes derived from PAN and their selective adsorption of organic dyes. Chinese Journal of Polymer Science, 2016. 34(1): p. 23-33.

[39] Langmuir, I., The constitution and fundamental properties of solids and liquids. II. Liquids. Journal of the American Chemical Society, 1917. 39(9): p. $1848-1906$.

[40] Freundlich, H., Über die adsorption in lösungen. Zeitschrift für physikalische Chemie, 1907. 57(1): p. 385-470.

[41] Ajenifuja, E., J.A. Ajao, and E.O.B. Ajayi, Adsorption isotherm studies of $\mathrm{Cu}$ (II) and Co (II) in high concentration aqueous solutions on photocatalytically modified diatomaceous ceramic adsorbents. Applied Water Science, 2017. 7(7): p. 3793-3801.

[42] Hameed, B.H., D.K. Mahmoud, and A.L. Ahmad, Sorption of basic dye from aqueous solution by pomelo (Citrus grandis) peel in a batch system. Colloids and Surfaces A: Physicochemical and Engineering Aspects, 2008. 316(1): p. 78-84.

[43] Huang, J.-H., et al., Adsorption of Rhodamine B and methyl orange on a hypercrosslinked polymeric adsorbent in aqueous solution. Colloids and Surfaces A: Physicochemical and Engineering Aspects, 2008. 330(1): p. 55-61.

[44] Saha, T.K., et al., Adsorption of methyl orange onto chitosan from aqueous solution. Journal of water resource and protection, 2010.2(10): p. 898.

[45] Chen, D., et al., Characterization of anion-cationic surfactants modified montmorillonite and its application for the removal of methyl orange. Chemical Engineering Journal, 2011. 171(3): p. $1150-1158$.

[46] Annadurai, G., R.-S. Juang, and D.-J. Lee, Use of cellulose-based wastes for adsorption of dyes from aqueous solutions. Journal of hazardous materials, 2002. 92(3): p. 263-274.

[47] Zhuannian, L., et al., Adsorption behavior of methyl orange onto modified ultrafine coal powder. Chinese Journal of Chemical Engineering, 2009. 17(6): p. 942-948.

[48] Zhu, H.-Y., R. Jiang, and L. Xiao, Adsorption of an anionic azo dye by chitosan $/$ kaolin $/ \gamma-\mathrm{Fe} 2 \mathrm{O} 3$ composites. Applied Clay Science, 2010. 48(3): p. 522-526.

[49] Iida, Y., et al., Sonochemically enhanced adsorption and degradation of methyl orange with activated aluminas. Ultrasonics, 2004. 42(1-9): p. 635-639.

[50] Küçükosmanoğlu, M., O. Gezici, and A. Ayar, The adsorption behaviors of Methylene Blue and Methyl Orange in a diaminoethane sporopollenin-mediated column system. Separation and Purification Technology, 2006. 52(2): p. 280-287.

This article is licensed under a Creative Commons Attriution 4.0 International License. 